\title{
Transformation of Brewery Subproducts into Valuable Biomass Using Mixotrophic Culture of Chlorella pyrenoidosa and Associated Bacteria
}

Néstor David Giraldo ${ }^{1 *}$

https://orcid.org/0000-0001-9017-1265

Raquel Juliana Romo Buchelly ${ }^{1}$

https://orcid.org/0000-0002-1681-8670

Danilo Echeverri Hincapié 1

https://orcid.org/0000-0001-7522-9289

\section{Lucia Atehortua ${ }^{1}$}

https://orcid.org/0000-0001-5502-1288

1Universidad de Antioquia, Grupo de Biotecnología, Sede de Investigación Universitaria S.I.U, Medellín, Colombia.

Received: 2019.04.10; Accepted: 2020.04.16.

*Correspondence: ndgiraldo@hotmail.com.

\section{HIGHLIGHTS}

- C. pyrenoidosa grows mixotrophically in brewery wastes.

- Removal of nitrate and phosphate obtained were up to $90 \%$ and $100 \%$ respectively

\begin{abstract}
To develop a biorefinery concept applied in the brewery industry, Chlorella pyrenoidosa and a consortium of associated bacteria were cultivated mixotrophically in a continuous photobioreactor using brewery low-value subproducts as an integrative process. Beer production residues were biochemically characterized to assess the most promising options to be used as a nutrient source for microalgal cultivation. Due to its physical and chemical properties, pre-treated weak wort was used to prepare an organic complex culture medium for microalgal biotransformation. Filtration and nitrogen supplementation were necessary to improve nutrient removal and biomass productivity. Maximal removal of nitrate and phosphate obtained were $90 \%$ and $100 \%$ respectively. Depending on operation conditions, total carbohydrates depuration ranged from $50-80 \%$. The initial concentration of total carbohydrates of the weak wort must be adjusted to $2-4 \mathrm{~g} / \mathrm{L}$ to maintain a stable equilibrium between microalgal and bacterial growth. The biochemical composition of produced biomass varied depending on the cultivation conditions as well as on its final use. Upon continuous mixotrophic conditions evaluated in this study, C. pyrenoidosa was composed mainly of carbohydrates and protein.
\end{abstract}

Keywords: Biorefinery; microalgae; bioproducts; bioeconomy; brewery. 


\section{INTRODUCTION}

Cervecería Unión is the biggest brewery in Colombia with an annual production of 26 million hectoliters, covering approximately $98 \%$ of sales in the market [1,2]. In the brewing process, there are different steps that generate a considerable quantity of solid, liquid and gaseous wastes. In most cases, these wastes have high organic loads and must be transported to wastewater treatment plants for their final disposal which implies additional costs for the process [3]. Therefore, it is important to look after new alternatives for giving value to these organic outputs that turn them into economic benefits. Each waste generated during beer production has a certain nutrient composition based on carbohydrates, nitrogen, phosphorus and other micronutrients that can be harnessed to carry out biotechnological processes generating new valuable products and simultaneously decreasing eutrophication potential.

Microalgae are photosynthetic microorganism whose biomass can be transformed into a wide range of bioproducts such as pigments, antioxidants, protein, carbohydrates, lipids and biopolymers with multiple applications on biofuel, pharmacy and food industry [4]. Depending on the strain, microalgae can use organic and inorganic carbon sources and light energy to develop a mixotrophic metabolism which allows higher growth rates in comparison with phototrophic and heterotrophic cultures [5]. Some of the most influential variables in microalgal production costs are the required nutrients for media preparation like nitrogen, phosphorus, magnesium, carbon and microelements. Integration of algal biomass production with industrial wastewater treatment is an attractive alternative for reduction of production costs and environmental negative impacts [6,7]. Chlorella pyrenoidosa is a fast growing green alga that has been widely studied for a number of biotechnological and commercial applications [8-11]. C. pyrenoidosa has been mainly cultivated axenically in phototrophic mode, however for wastewater treatments it is difficult to keep only one predominant organism, especially on open cultivation systems. Accordingly, co-cultivation or consortium cultivation strategies showed to be the most feasible alternative as microalgae provide oxygen for organic matter degradation and bacterial consortium provide mineralization of complex substrates and carbon dioxide for algal development[3]. In this work we assessed for the first time, the technical suitability of using $C$. pyrenoidosa and its associated bacteria to transform brewery wastes into higher value products with different modes of operation in photobioreactor. The most relevant wastes were identified and valued as nutrient source and a series of optimization steps were performed to improve depuration capacity and biomass production.

\section{MATERIAL AND METHODS}

\section{Microalgal Strain}

Chlorella pyrenoidosa was purchased from Canadian Phycological Culture Centre (CPCC). Microalgal maintenance cell cultures were incubated in conical flask with $100 \mathrm{~mL}$ of $B_{11}$ medium [12] homogenized in orbital shaker at $100 \mathrm{rpm}$ with continuous illumination $\left(90 \mu \mathrm{E} / \mathrm{m}^{2} \mathrm{~s}\right)$ provided by cool white fluorescent lamps. $\mathrm{pH}$ and temperature were not controlled although the latter remained stable around $25^{\circ} \mathrm{C} . \mathrm{CO}_{2}$ was provided on daily basis as the carbon source by means of a one-minute pulse at an approximate flux of $1.0 \mathrm{~L} / \mathrm{min}$. All experiments were inoculated with active growing cells from maintenance cultures at a final concentration of $0.15-0.25 \mathrm{~g} / \mathrm{L}$.

\section{Identification and characterization of residues}

A complete review of the main process wastes, and sub-products was performed in the local brewery "Cervecería Unión". Parameters such as state of the waste, process of generation, final disposal, total discharges and chemical additives were provided by the company. From that pool of products, solid and gaseous substances were not considered because all of them are currently recycled into the process or sold for different purposes. On the other hand, liquid wastes were analyzed in terms of their suitability as a nutrient source for microalgae. Turbidity, total organic carbon (TOC), total nitrogen and phosphorus, nitrate, ammonia-derived nitrogen, chemical oxygen demand (COD), biological oxygen demand (BOD5), sulfates and dissolved solids were determinate according to standard methods indicated in the supplementary material 1. 


\section{Microalgae culture conditions}

\section{Waste conditioning schemes}

The high solid charge and turbidity of the waste evaluated made necessary to apply initial pretreatments to improve the physical and chemical properties for microalgae culture. Accordingly, we evaluated the effect of different conditioning schemes in terms of microalgal growth, nutrient removal and final biomass composition using mixotrophic cultures. Filtration (standard cellulose membrane filter - Advantec), $\mathrm{pH}$ adjustment $(7-8)$, dilution (50\% with tap water) and nitrogen supplementation (to adjust a N:P ratio of $5: 1$ ) were evaluated as pre-treatment procedures as suggested by Mukherjee and coauthors [13]. Additionally, some of the treatments included sterilization at $121^{\circ} \mathrm{C}$ for 20 minutes. Photoautotrophic culture with $\mathrm{BG}_{11}$ medium was used as a reference control. Each treatment was evaluated by triplicate in conical flasks of 500 $\mathrm{mL}$ with $200 \mathrm{~mL}$ of effective volume, at $100 \mathrm{rpm}$ stirring, exposure to continuous light with cool white fluorescent lamps $\left(90 \mu \mathrm{E} / \mathrm{m}^{2} \mathrm{~s}\right)$, room temperature $\left(25^{\circ} \mathrm{C}\right)$, filter-sterilized $\mathrm{CO}_{2}$ was injected at a flowrate of $1.0 \mathrm{~L} / \mathrm{min}$ and the $\mathrm{pH}$ was not controlled. Cultures were incubated for during eight days.

\section{Evaluation of carbohydrates concentration in the waste on the cell growth and depuration capacity}

With the basis on the analysis of composition of the liquid wastes, specially of the weak worth generated during the process of different types of beer, we found out that the COD could be very variable, mainly due to the carbohydrates concentration in the liquid. Therefore, it was necessary to decide whether algal culture is tolerant to significant variations in medium composition or it must be adjusted to a narrower interval. In that sense, the effect of different concentrations of carbohydrates in the weak worth on the growth and removal capacity of $C$. pyrenoidosa was studied. Five dilutions of weak worth ranging from 2 to $10 \mathrm{~g} / \mathrm{L}$ of total carbohydrates were evaluated. The N:P ratio was adjusted to $5: 1$ based on the measured phosphorous content. Nutrient concentration, microalgal growth and final biochemical composition of biomass were tested. Cultures were incubated in a $500 \mathrm{~mL}$ Erlenmeyer flask with an effective volume of $200 \mathrm{~mL}$ under identical conditions as described in prior section.

\section{Effect of photon flux density on depuration capacity in a continuous photobioreactor culture}

The cell growth and nutrient removal from the brewery waste were evaluated at photobioreactor level operating in continuous mode. However, considering that the light availability is crucial for cell development, oxygen evolution and organic compounds degradation, we evaluated three illumination conditions (150, 325 and $450 \mu \mathrm{E} / \mathrm{m}^{2} \mathrm{~s}$ ) to identify at which extent the light can promote depuration capacity in mixotrophic cultures. A $1 \mathrm{~L}$ BioFlo /CelliGen 115 (New Brunswick) stirred tank bioreactor was modified to incorporate LED panels (Sylvania P24645, 6500K) and operated with a constant volume of $900 \mathrm{ml}$. For each condition, a batch culture of $C$. pyrenoidosa was started photoautotrophically in modified $B_{11}$ medium (N:P ratio 5:1) and incubated for four days. Afterwards, the continuous operation started with fresh medium injection and level control by overflow. The dilution rate was $0.32 \mathrm{~d}^{-1}, \mathrm{pH}$ was controlled at 8 , air enriched with $2.5 \% \mathrm{CO}_{2}$ was supplied at $0.1 \mathrm{VVM}$ and temperature was not controlled but remained constant around $25^{\circ} \mathrm{C}$.

\section{Monitoring culture and analytical methods}

In all experiments, cell growth was monitored as the changes in $750 \mathrm{~nm}$ OD using a plate spectrophotometer (Biotek Powerwave SX2). Nitrate, phosphate and total carbohydrates were measured spectrophotometrically using the methods described by Cataldo [14], Strickland and Parsons [12] and Dubois [15] respectively. The standard curves used to relate the absorbance and the nutrient concentration showed a linear correlation fit $\left(0,9933 \leq \mathrm{R}^{2} \leq 0,9974\right)$. At the end of each experiment, cell concentration was evaluated gravimetrically to estimate biomass productivity. Additionally, the biochemical composition of the biomass was also assessed. Total soluble carbohydrates were extracted from the dry biomass for acid hydrolysis in cold water as was proposed by Myklestad and Haug [16], the carbohydrate quantification was done spectrophotometry by the method of Dubois [15]. Total lipids were estimated gravimetrically according to the method described by Bligh and Dyer [17]. Total soluble protein was estimated spectrophotometrically according to the method described by Lowry [18]. Ash content was measured as the residue after ignition at $500{ }^{\circ} \mathrm{C}$ overnight. 


\section{RESULTS AND DISCUSSION}

\section{Identification, characterization and selection of brewery wastes generated at Cervecería unión s.a}

In the brewing process studied in this work, different wastes are generated, most of which are organic compounds, including solids, liquids and gases. On the other hand, large quantities of packaging wastes (glass, cardboard, plastic and metal) from operations of receiving raw materials and bottling are also generated and managed according to local regulations. Organic wastes such as bagasse (also named beer bran), weak wort and yeast are considered as by-products because these are valued by other industries, for instance the animal feed industry or agricultural use as an organic fertilizer. Besides of the wastes in the manufacturing process, a large volume of wastewater is generated, especially in cleaning operations (CIP's) and bottling, these have high organic load, suspended solids and strongly alkaline $\mathrm{pH}$ due to rinses with $\mathrm{NaOH}$. In this wastewater, drains from kitchens and toilets are present as well. The emissions to atmosphere are primarily steam and volatile compounds during wort boiling, combustion gases $\left(\mathrm{CO}_{2}, \mathrm{NO}_{\mathrm{x}}, \mathrm{SO}_{\mathrm{x}}\right)$ in boilers, particles in receiving operations and transport of malt and sporadic leaks of refrigerant. The carbon dioxide produced during the fermentation and maturation of beer is recovered by $95 \%$ for further operations, therefore carbon dioxide does not represent a significant source of emissions. The brewing process in the "Cervecería Union" runs by consecutive batches for all beer references all year round so the physical and biochemical characteristics of wastes derived from each process vary from one batch to another. A list of main brewing processes and their corresponding subproducts and wastes are described in the supplementary material 2. Malt husk, weak wort, residual yeast and dust of malt are the major wastes generated raising rates up to $2545 \mathrm{~T} / \mathrm{month}, 740 \mathrm{~T} / \mathrm{month}, 147 \mathrm{~T} / \mathrm{month}$ and $10 \mathrm{~T} / \mathrm{month}$ respectively. Solid wastes are not suitable to be used as the nutrient source for microalgae culture because it would require previous milling, hydrolysis and neutralization processes which represents a higher investment in infrastructure and operation. Additionally, some of these sub-products are occasionally commercialized as raw materials for feed production. The carbon dioxide generated is recycled for other processes in the plant, so its availability is limited for algal culture and it does not represent a significant atmospheric emission.

Considering that, weak wort, residual yeast and the wastewater were chemically characterized aiming to assess their suitability for microalgal culture. As summarized in table 1, residual yeast has a high nitrogen content (expressed as $94.98 \mathrm{mg} \mathrm{NO}_{3}^{-} / \mathrm{L}, 145.71 \mathrm{mg} \mathrm{NH}_{3} / \mathrm{L}$ ) and phosphorus content of $1275.00 \mathrm{mg} \mathrm{P/L}$. The BOD5 / COD value of 0.49 was lower than that found for in other products indicating a lower biodegradation efficiency. Turbidity was other key factor analyzed, being 2160 NTU for residual yeast, 330 NTU for weak wort and 160 NTU for wastewater. Although residual yeast has a higher nutrient content, it causes a severe attenuation of incident light needed for photosynthesis of microalgae. This fact represents a major drawback towards its use as a microalgal culture media component. Weak wort has a higher BOD5/COD ratio, total nitrogen and phosphorus concentration than those estimated in wastewater (Table 1). It is worth to mention that in the case of the nitrogen, weak wort and wastewater have a low ammonium and nitrate content, meaning that the nitrogen is mainly present as aminoacids. Microalgae have a greater preference for inorganic nitrogen sources, however, they can also use organic nitrogen sources [19,20]. Similarly Zheng and coauthors [7] characterized different wastewaters derived from the beer production process (malting, fermentation, and packaging) and also found a low content of ammonium, phosphate and total nitrogen, therefore this water must be supplemented (or mixed with other liquid wastes) to compensate deficient nutrients. Moreover, the weak wort has added zinc and calcium, which are important micronutrients for microalgal metabolism. Therefore, the weak wort is found to be the most suitable brewery waste to be treated and transformed using microalgae cells considering its composition, availability, biodegradability and turbidity. On the other hand, it is also important to mention that this substrate is considered as safe because of the absence of pathogens, dangerous or regulated substances. 
Table 1 Physical and chemical parameters of brewery wastes

\begin{tabular}{|c|c|c|c|}
\hline PARAMETER & $\begin{array}{l}\text { WEAK WORT } \\
\text { (WW) }\end{array}$ & $\begin{array}{c}\text { WET } \\
\text { YEAST } \\
\text { (Hydrolysate) }\end{array}$ & WASTEWATER \\
\hline State & Semi-Liquid & Semi-Liquid & Liquid \\
\hline Frequency of generation & Daily & Daily & Daily \\
\hline Special additives & $\begin{array}{l}\text { Calcium chloride, } \mathrm{Zn} \\
\text { as cofactor, hop } \\
\text { extract }\end{array}$ & - & - \\
\hline pH & $3.5-5$ & - & - \\
\hline Sulfate $\left[\mathrm{mgSO}_{4}-/ \mathrm{ll}\right]$ & 7.79 & 23.00 & 240.68 \\
\hline Nitrate $\left[\mathrm{mgNO}_{3}-/ \mathrm{l}\right]$ & 0.56 & 94.98 & 0.50 \\
\hline Total organic carbon (TOC) [mgC/l] & 3878.40 & 49457.50 & 1515.90 \\
\hline Dissolved solids [mg/l] & 12500.00 & 54760.00 & 3232.00 \\
\hline Biological oxygen demand-bod5 $[\mathrm{mg} \mathrm{O} / \mathrm{l}]$ & 18000.00 & 38000.00 & 18000.00 \\
\hline Chemical oxygen demand-cod $\left[\mathrm{mgO}_{2} / \mathrm{l}\right]$ & 20473.00 & 76610.70 & 31940.30 \\
\hline $\begin{array}{l}\text { Bod5/ cod } \\
\text { Ammoniacal nitrogen [mg NH} 3-n / l]\end{array}$ & $\begin{array}{c}0.88 \\
<5.00\end{array}$ & $\begin{array}{c}0.49 \\
145.71\end{array}$ & $\begin{array}{l}0.56 \\
<5.00\end{array}$ \\
\hline Total nitrogen Kjeldahl [mg N/l] & 265.01 & 4499.04 & 55.82 \\
\hline Total phosphorus [mg P/l] & 88.00 & 1275.00 & 10.09 \\
\hline Turbidity [NTU] ${ }^{\star}$ & 330.00 & 2160.00 & 160.00 \\
\hline
\end{tabular}

${ }^{*}$ Nephelometric Turbidity Units (3 NTU $=1$ ppm SiO 2$)$

\section{Weak wort conditioning schemes}

Cultivation of $C$. pyrenoidosa with differently pretreated culture media showed a variation in growth parameters as shown in Table 2. In mixotrophic cultures, the unfiltered weak wort supplemented with nitrogen produced a lower final biomass concentration and productivity $(2.57 \mathrm{~g} / \mathrm{L}, 0.286 \mathrm{~g} / \mathrm{L} \mathrm{d}$ respectively) when compared with filtered cultures $(2.9 \mathrm{~g} / \mathrm{L}$ and $0.33 \mathrm{~g} / \mathrm{L} \mathrm{d})$. However, the lowest concentration of biomass and productivity were obtained in the photoautotrophic culture $(1 \mathrm{~g} / \mathrm{L}$ and $0.111 \mathrm{~g} / \mathrm{L} \mathrm{d})$. Zhang and coauthors obtained similar results and concluded that the addition to the culture medium of maltose, the predominant carbohydrate in the brewery waste, generates an increase in the growth of the microalga compared with the culture in photoautotrophic conditions.

Table 2.Growth parameter of microalgae $C$. pyrenoidosa under different condition of filtration and addition of nitrogen to the weak wort medium. Autotrophic culture was performed in $\mathrm{BG}_{11}$ medium.

\begin{tabular}{lccccc}
\hline \multicolumn{1}{c}{ Growth parameter } & WWF & WWF 50\% & WW & WW 50\% & Autotrophic \\
& $\mathbf{5 0 \% + \mathbf { N }}$ & & $\mathbf{5 0 \%}+\mathbf{N}$ & & \\
\hline Biomass (g/ / ) & $2.98 \pm 0.06$ & $2.93 \pm 0.09$ & $2.87 \pm 0.11$ & $2.57 \pm 0.05$ & $1.00 \pm 0.1$ \\
Biomass productivity (g/ L d) & $0.33 \pm 7 \mathrm{E}-3$ & $0.33 \pm 8 \mathrm{E}-3$ & $0.32 \pm 0.01$ & $0.28 \pm 0.01$ & $0.11 \pm 0.01$ \\
$\boldsymbol{\mu}_{\max }\left(\mathbf{d}^{-1}\right)$ & $0.60 \pm 0.01$ & $0.60 \pm 0.03$ & $0.15 \pm 0.01$ & $0.17 \pm 0.02$ & $0.28 \pm 0.01$ \\
\hline
\end{tabular}

Regarding on the growth rate, cultures with filtered media reached rates up to $0.6 \mathrm{~d}^{-1}$, higher than those obtained in cultures without filtration pre-treatment $\left(0.15-0.17 \mathrm{~d}^{-1}\right)$ and photoautotrophic cultures $\left(0.28 \mathrm{~d}^{-1}\right)$. These data suggest that filtration step is fundamental to increase light availability and photosynthetic activity. Some authors have shown that mixotrophic microalgal cultures are more efficient than heterotrophic and phototrophic cultures [21-23]. Furthermore, Wang and coauthors [24] suggest that under mixotrophic conditions, algal energy metabolism is not limited by photosynthesis because organic compounds can act as carbon and energy, decreasing the dependency of energy from photosynthesis and reducing the effects of photolimitation and photoinhibition. Overcoming such metabolic limitations, allows a faster cell proliferation[5,25,26]. The cultures used in our trials were not axenic, however, the consortium algae/bacteria helped the consumption of carbohydrates and nutrients as a mutual symbiotic system, nevertheless, it is difficult to determine the specific removal contribution of each microorganism because microalgal cells fix and release carbon and oxygen as a product of the simultaneous photosynthesis and respiration[27,28]. As shown in Figure 1A, C. pyrenoidosa adapted easily to mixotrophic conditions. 


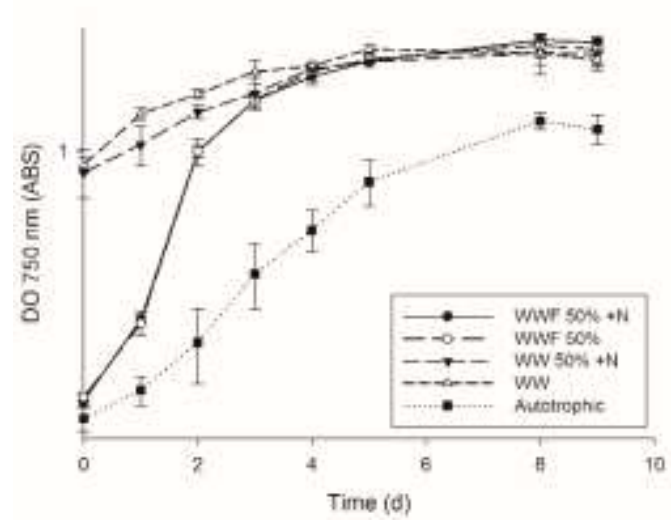

(a)

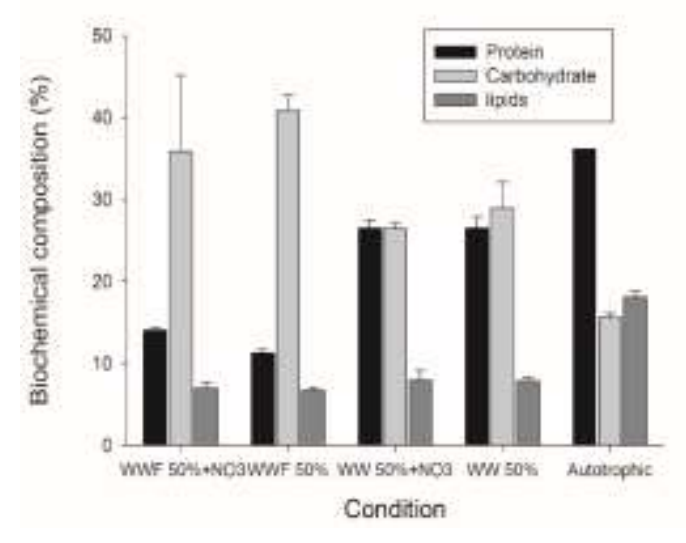

(b)

Figure 1. Kinetic of growth (a) and Biochemical composition (b) of microalgae C. pyrenoidosa culture under different condition of filtration and addition of nitrogen to the weak wort medium. Autotrophic culture was performed in BG 11 medium.

Regarding the biochemical composition of the biomass, in the case of the photoautotrophic culture (used as a control) the protein is the main component. In the unfiltered weak wort carbohydrates and proteins contents are similar; in contrast, in cultures pretreated by filtration, carbohydrates are preferentially produced over proteins (Figure 1B). Lipid content in mixotrophic conditions is similar for all evaluated pretreatments, but lower than those accumulated under photoautotrophic conditions. This suggests that under the mixotrophic culture of $C$. pyrenoidosa, the availability of organic carbon induces the accumulation of carbohydrates rather than lipids. The biochemical composition of the biomass obtained was also affected by the culture conditions, mainly due to the effect of the filtration pretreatment. Although the filtration process favors the growth of the cells by allowing a better use of light as a consequence of the clarification of the medium, it also has an adverse effect and generates a nitrogen deficiency, since removal of dissolved proteinrich solids from the wort, eliminates a significant concentration of organic nitrogen that is believed to be the cause of the great difference in the composition of lipids, carbohydrates and proteins in the cell. In the case of the $\mathrm{BG}_{11}$ medium, where there is a high nitrogen content, the cells direct their metabolism towards the production of proteins, however in the filtered wort the availability of total nitrogen is low, leading a high accumulation of storage metabolites mainly made out of carbon [29-31].

The addition of nitrate in the culture medium made with weak wort filter did not affect the cell growth and the biomass production $(P$ - value $>0.05)$. However, as shown in Table 3, the addition of nitrate increases the biological removal capacity of the total carbohydrates at the end of the batch from $86.91 \%$ to $91.54 \%$. Nitrate removal was total for all media formulations in mixotrophic cultures and $30.71 \%$ for the photoautotrophic culture that has phosphorus as a limiting nutrient. The removal of phosphate was lower in unfiltered media; the high turbidity causes a strong light attenuation into the culture limiting photosynthetic activity. The high removal rates obtained in this study are similar to those presented by Zhen and coauthors from conical flasks trials growing in which $C$. vulgaris was evaluated under different conditions of brewery and piggery wastewater mixtures. According to the above, we found out that nitrogen addition in a 1:5 ratio with phosphorous and medium filtering are the most suitable pretreatment steps to favor the growth and nutrient removal for $C$ pyrenoidosa when using brewery effluents.

Table 3. Removal percentage (\%) of $\mathrm{PO}_{4}-, \mathrm{NO}_{3}$ - and Carbohydrates in different waste conditioning schemes evaluated with $C$. pyrenoidosa. Autotrophic culture was performed in $\mathrm{BG}_{11}$ medium.

\begin{tabular}{|c|c|c|c|c|c|}
\hline \multicolumn{6}{|c|}{ \% REMOVAL } \\
\hline \multirow{2}{*}{ Nutrient } & \multicolumn{2}{|c|}{ WWF $50 \%$} & \multicolumn{2}{|c|}{ WW 50\% } & \multirow{2}{*}{ Autotrophic } \\
\hline & Add $\mathrm{NO}_{3}$ & - & Add $\mathrm{NO}_{3}$ & - & \\
\hline $\mathrm{PO}_{4}^{-}$ & 100.00 & 100.00 & $87.82 \pm 8.36$ & $83.10 \pm 7.82$ & $99.70 \pm 0.52$ \\
\hline $\mathrm{NO}_{3}^{-}$ & 100.00 & 100.00 & 100.00 & 100.00 & $30.71 \pm 4.47$ \\
\hline Carbohydrates & $91.54 \pm 1.50$ & $86.91 \pm 2.29$ & $90.51 \pm 3.81$ & $90.12 \pm 3.85$ & - \\
\hline
\end{tabular}

${ }^{*} \mathrm{BG}_{11} \mathrm{NO}_{3}^{-1} \mathrm{~g} / \mathrm{L}, \mathrm{PO}_{4}^{-2} 20 \mathrm{mg} / \mathrm{L}$ 


\section{Effect of light intensities in a continuous culture in stirred tank bioreactor}

Light quality and availability play a fundamental role in the fixation of inorganic carbon during photosynthesis, so it is one of the main variables to be studied for microalgae culture optimization, especially in photoautotrophic cultures. However, there is limited information regarding on the effect of light intensity in continuous cultures under mixotrophic conditions. In this study we evaluated the effect of three irradiance levels on the growth and nutrient removal capacity of Chlorella pyrenoidosa. Each culture was started in batch photoautotrophic mode for 3 days. During this time, the behavior in cell growth was similar for all treatments. When the nutrients $(\mathrm{N}$ and $\mathrm{P})$ in the medium were depleted, the continuous operation was started by feeding culture medium prepared with weak wort $50 \%$ at a constant dilution rate $0,32 \mathrm{~d}^{-1}$. At the beginning, in all the treatments, the cell density showed some fluctuations and then stabilized, as can be seen in Figure $2 \mathrm{~A}$. This indicates that the dilution rate used was adequate to avoid washout or biomass accumulation.

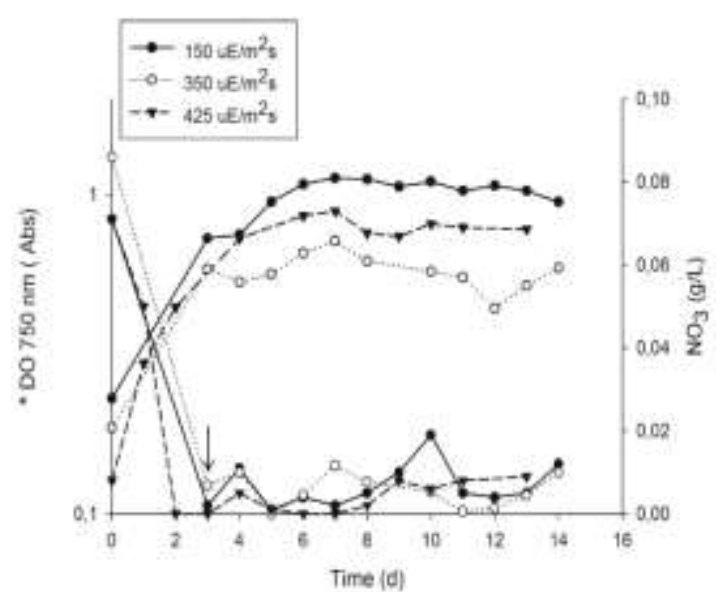

(a)

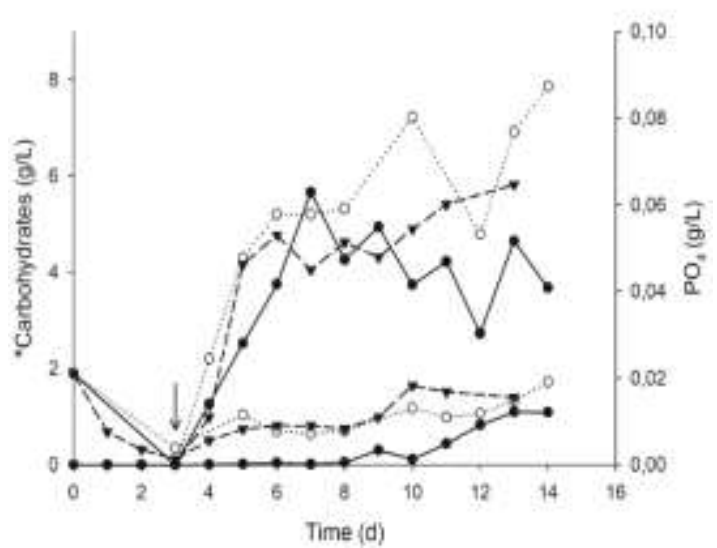

(b)

Figure 2. Growth and $\mathrm{NO}_{3}$ - kinetics (a), Carbohydrates and $\mathrm{PO}_{4}$ - kinetics (b) of $C$. pyrenoidosa culture with different light intensities in continuous bioreactor. The arrow corresponds to the transition from batch to continuous culture.

The nitrate removal by the microalga-bacteria consortium was effective (>90\%) with the three light levels evaluated (Figure 2A). On the other hand, the efficiency in phosphate removal decreased few days after continuous operation started and it is related with the irradiance (Figure 2B). On the last day of culture, phosphate removal ranged from $41.82 \%$ in $350 \mu \mathrm{E} / \mathrm{m}^{2} \mathrm{~s}$ to $65.98 \%$ using a light intensity of $150 \mu \mathrm{E} / \mathrm{m}^{2} \mathrm{~s}$ (Table 4). This difference in phosphorus removal could be related with nitrogen deficiency during continuous cultivation, since the consumption of phosphorus is strongly linked to the availability of nitrogen [32]. Zheng and coauthors [7] published a work with wastewater from the brewing industry and showed that once the nitrogen is completely depleted, removal of remaining phosphate and carbohydrates stops.

Table 4. Removal percentage of $\mathrm{PO}_{4}^{-}, \mathrm{NO}_{3}{ }^{-}$and Carbohydrates in the different photon flux density with $C$. pyrenoidosa

\begin{tabular}{llll}
\hline \multicolumn{4}{c}{ \% REMOVAL } \\
\hline PFD $\left(\boldsymbol{\mu E} / \mathbf{m}^{2} \mathbf{s}\right)$ & $\mathbf{1 5 0}$ & $\mathbf{3 5 0}$ & $\mathbf{4 3 0}$ \\
$\mathrm{PO}_{4}{ }^{-}$ & 65.98 & 41.82 & 58.40 \\
$\mathrm{NO}_{3}{ }^{-}$ & 96.41 & 93.18 & 90.77 \\
Carbohydrates & 59.99 & 23.2 & 51.98 \\
\hline
\end{tabular}

The total sugars concentration in the weak wort fed to the reactor varied between 6 and $12 \mathrm{~g} / \mathrm{L}$. From the beginning of the continuous operation, the sugars in the medium started to increase until a stable value after two days of feeding as shown in Figure 2B. The final removal of carbohydrates for light intensities of 150,350 and $430 \mu \mathrm{E} \mathrm{/} \mathrm{m}^{2}$ was $59.99 \%, 23.2 \%$ and $51.98 \%$ respectively. Zhang and coauthors reported that Chlorella pyrenoidosa shows a low affinity to maltose in relation to other substrates such as glucose, galactose and fructose, suggesting that this strain might need a longer retention time to consume the sugars on this substrate. Continuous operation in the bioreactor was stable during 14 days, however, after that point bacterial growth was strongly favored due to the high sugars concentration and oxygen produced by microalga, this decreased the microalgal proliferation as a result of light attenuation and toxic substances accumulation in the culture medium which were not washed out despite continuous injection of fresh medium and harvest [33]. Salati and coauthors reported a high concentration of bacteria in microalgal mixotrophic 
continuous cultures, which were kept stable for 18 days. Our results show that continuous illumination at 150 $\mu \mathrm{E} / \mathrm{m}^{2}$ causes the highest biomass concentration and removal of nitrate, phosphate and carbohydrates.

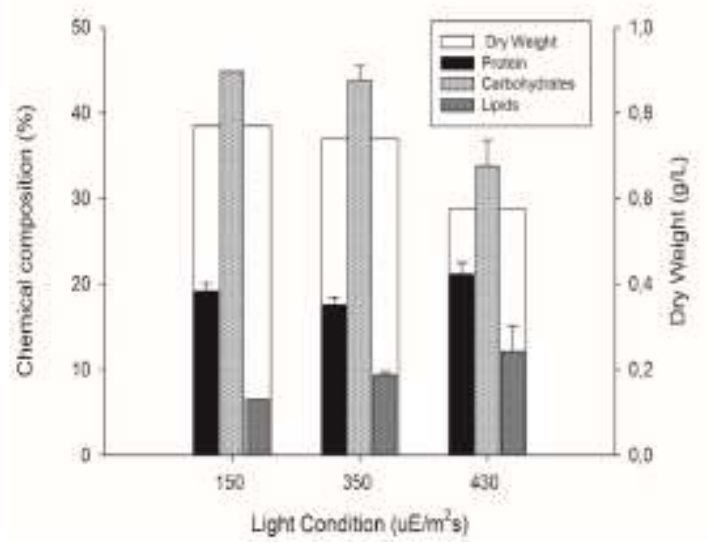

Figure 3. Chemical composition of Chlorella pyrenoidosa biomass grown in different light intensity

The final concentration of biomass, showed an inverse relationship with photo flux density (Figure 3) and the highest concentration of biomass obtained was $0.8 \mathrm{~g} / \mathrm{L}$. In other studies, Salati and coauthors ran a continuous mixotrophic culture of Chlorella vulgaris using a mixture of agroindustry subproducts such as glycerol, cheese whey and wine solids with synthetic $B_{11}$ medium. They obtained biomass concentrations between 1.67 and $2.59 \mathrm{~g} / \mathrm{L}$. This difference might rely on the sugar profile of these by-products or the fact that they use a rich synthetic medium as diluting agent for the agro-industrial byproducts. In our case, only an adjustment is made in the radio N: P. Cheirsilp y Torpee (2012) obtained an increase in the biomass concentration of Chlorella $s p$ in mixotrophic cultures as a response to a gradual increase in light intensity up to $100 \mu \mathrm{E} / \mathrm{m}^{2} \mathrm{~s}$. Over $133 \mu \mathrm{E} / \mathrm{m}^{2} \mathrm{~s}$ the growth rate and biomass concentration started to fall. On the other hand, in an analysis of metabolic flow in microalgae, Yang and coauthors [34] concluded that the energy supplied as light is more difficult to be trapped and converted to ATP than the energy obtained from dissolved organic carbon in the medium. They also found that the presence of carbohydrates in the culture medium reduces the photosynthetic capacity of the microalga, which shows that where there is a high availability of organic carbon, the use of low light intensities does not play a limiting role in energy metabolism as in the case of phototrophic cultures. Accordingly, under mixotrophic conditions lower values of photon flux density are suitable to maintain photosynthetic and respiratory pathways active. Protein content of the cultures irradiated with $150 \mu \mathrm{E} / \mathrm{m}^{2} \mathrm{~s}$ and $350 \mu \mathrm{E} / \mathrm{m}^{2} \mathrm{~s}$ were similar. Nevertheless, at $430 \mu \mathrm{E} / \mathrm{m}^{2} \mathrm{~s}$ showed a higher protein content (Figure 3). In contrast, carbohydrates showed a different response passing from $44.86 \%$ to $33.8 \%$ with the minimum and maximum photon flux density respectively. On the other hand, the gradual increase in light intensity favored the accumulation of total lipids, varying from $6.55 \%$ with $150 \mu \mathrm{E} / \mathrm{m}^{2} \mathrm{~s}$, $9.39 \%$ with $350 \mu \mathrm{E} / \mathrm{m}^{2} \mathrm{~s}$ and maximum $12.16 \%$ with $430 \mu \mathrm{E} / \mathrm{m}^{2} \mathrm{~s}$. The ash content of the biomass varied between $10-15 \%$. Ren and coauthors [26] reported that Scenedesmus sp. incubated in mixotrophic conditions, improved lipid accumulation as a response in light intensity increase until below saturation point from that point they observed a decrease in the accumulation of lipids. Likewise, Cheirsilp and Torpee (2012) reported a similar result in Chlorella pyrenoidosa but an opposite outcome for Nannochloropsis sp., indicating that the relationship between light and lipid accumulation depends on the strain and is not a common response [25].

\section{Effect of initial carbohydrates concentration on growth and nutrient removal}

Weak wort composition varies according to each beer brand produced, being total sugars one of the most important variables to evaluate in terms of growth and nutrient removal with a microalgal system. In this study we evaluated carbohydrates concentration ranging from $2 \mathrm{~g} / \mathrm{L}$ up to $10 \mathrm{~g} / \mathrm{L}$. These concentrations in the weak wort were obtained by dilution with tap water. At the end of the culture, when the cells reached the stationary phase (Figure $5 \mathrm{~A}$ ), in cultures started with $2-4 \mathrm{~g} / \mathrm{L}$ of total carbohydrates were colonized mainly by microalgae, in contrast, in cultures started with concentrations above $6 \mathrm{~g} / \mathrm{L}$ bacterial growth was predominant (Figure 4). Andruleviciute and coauthors [35] showed that some algal strains such as Scenedesums, Nannochloris and Chlorella are inhibited when the culture medium has a carbohydrate concentration above $5 \mathrm{~g} / \mathrm{L}$. In our study, we found out that carbohydrates concentrations ranging from $2 \mathrm{~g} / \mathrm{L}-4 \mathrm{~g} / \mathrm{L}$ are suitable for mixotrophic continuous culture of Chlorella pyrenoidosa in terms of algal/bacterial balance and growth. 


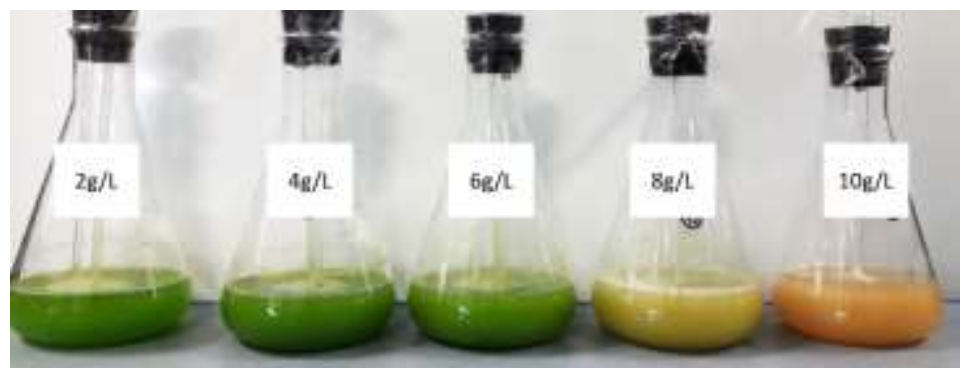

Figure 4. Photograph taken after $8 \mathrm{~d}$ of culture of $C$. pyrenoidosa at different concentrations of total sugars.

Under these conditions, carbohydrates removal are $82,87 \%$ and $80,39 \%$ for $2 \mathrm{~g} / \mathrm{L}$ and $4 \mathrm{~g} / \mathrm{L}$ respectively and for $10 \mathrm{~g} / \mathrm{L}$ was $63,97 \%$. Regarding on inorganic nutrient removal, nitrate and phosphate were completely consumed after three days of cultivation in media with $2-4 \mathrm{~g} / \mathrm{L}$, for $6-8 \mathrm{~g} / \mathrm{L}$ those were removed after 6 days and with the highest concentration of $10 \mathrm{~g} / \mathrm{L}$ nutrient removal was not complete (Figure 5). Cheirsilp and Torpee obtained a total removal of carbohydrates at $2-4 \mathrm{~g} / \mathrm{L}$ with Chlorella, however in that case the mixotrophic medium was prepared with glucose, which is easily assimilated and consumed the cells. In this study, the weak wort has a complex mixture of hexoses, pentoses and disaccharides that make difficult its total and rapid consumption.

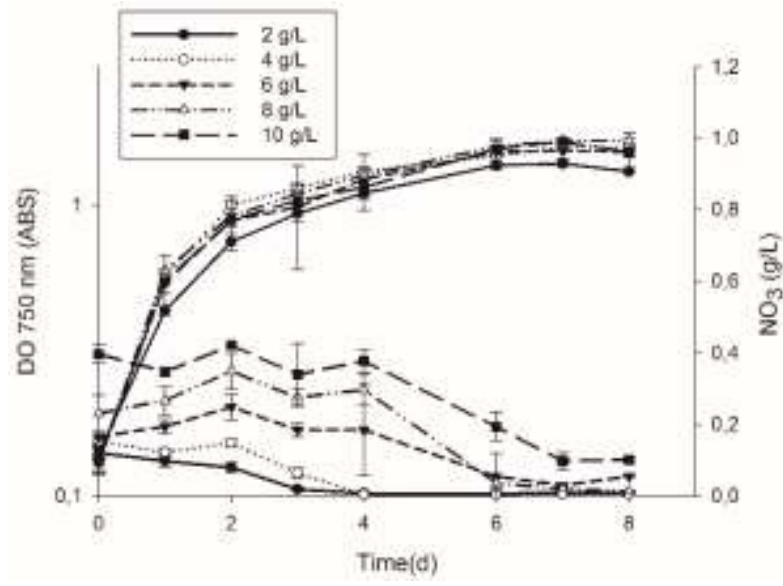

(a)

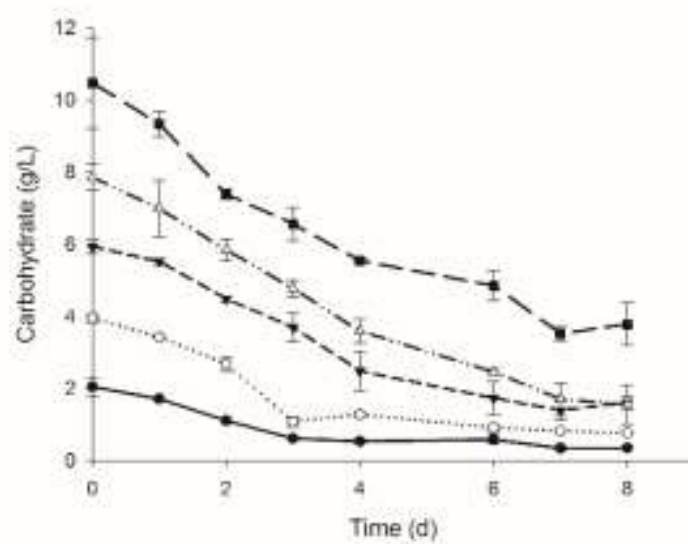

(b)

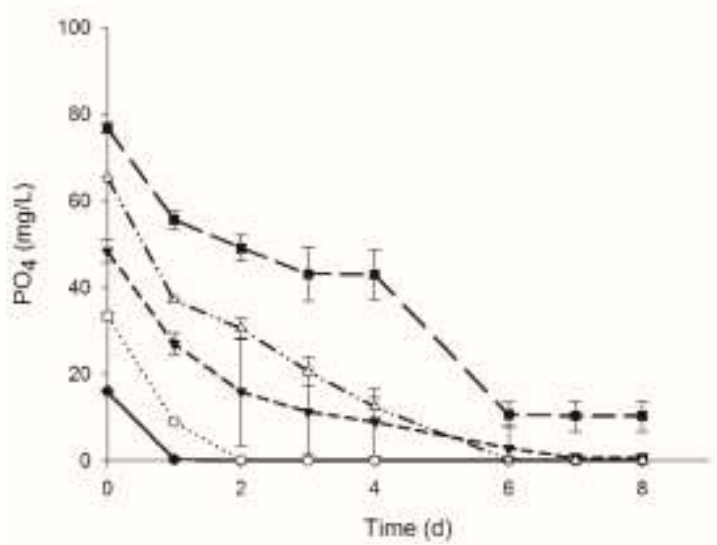

(c)

Figure 5. Growth and $\mathrm{NO}_{3}-$ (a), Carbohydrates (b) and $\mathrm{PO}_{4}-$, (c) kinetics of $\mathrm{C}$. pyrenoidosa culture different concentrations of total sugars.

Maximal biomass production obtained was $2.57-2.63 \mathrm{~g} / \mathrm{L}$ for $4 \mathrm{~g} / \mathrm{L}$ and $8 \mathrm{~g} / \mathrm{L}$ respectively, whilst the lowest was $1.87 \mathrm{~g} / \mathrm{L}$ of biomass with $2 \mathrm{~g} / \mathrm{L}$. Nevertheless, with concentrations higher than $4 \mathrm{~g} / \mathrm{L}$ most of the biomass is produced by bacterial growth. The biomass/substrate yield $Y_{x / s}$ was $0,94 g_{\text {biomass }} / g_{\text {carbohydrates }}$ at $2 \mathrm{~g} / \mathrm{L}$ and showed an inverse relationship with carbohydrate concentration as shown in Table 5. 
Table 5. Biomass concentration and biomass-substrate rate of $C$. pyrenoidosa at different initial concentrations of total sugars

\begin{tabular}{cccccc}
\hline CHO Concentration & $\mathbf{2} \mathbf{~ g / L}$ & $\mathbf{4 g} / \mathbf{L}$ & $\mathbf{6 g} / \mathbf{L}$ & $\mathbf{8 g} / \mathbf{L}$ & $\mathbf{1 0} \mathbf{~} / \mathbf{L}$ \\
\hline Biomass $(\mathbf{g} / \mathbf{L})$ & $1.87 \pm 0.11$ & $2.5 \pm 0.42$ & $2.35 \pm 0.52$ & $2.63 \pm 0.29$ & $2.17 \pm 0.11$ \\
\hline $\mathbf{Y x} / \mathbf{s}\left(\mathbf{g}_{\text {biomass }} / \mathbf{g}_{\text {carbohydrates }}\right)$ & $0.94 \pm 0.01$ & $0.79 \pm 0.01$ & $0.53 \pm 0.02$ & $0.41 \pm 0.03$ & $0.35 \pm 0.03$ \\
\hline
\end{tabular}

These results show the feasibility of integration of a multi-step process involving beer and microalgae biomass production under specific operational conditions. Although there is a wide spectrum of different wastes and low value sub-products generated in breweries, only few options are suitable to be used as a substrate for microalgal culture considering high organic loads, turbidity, reutilization into the process or energy intensive preprocessing and pre-conditioning requirements. In this study we performed a complete evaluation of the wastes generated in the plant and only the weak wort fits the most important conditions to be used as nutrient source for microalgae growth and transformation into bioproducts. Despite its adequate characteristics, this substrate cannot be used directly into the microalgal culture and some conditioning steps are required like $\mathrm{pH}$ adjustment, filtration and dilution because those variables resulted to be critical for cell development. As shown above, lower carbohydrate concentrations allow better removal efficiency, biomass productivity and yields. Lower organic loads favor light transmission into the culture improving photosynthetic activity, oxygen production and algal growth, this help bacteria to aerobically degrade organic compounds without an over production of bacterial biomass. This equilibrium is needed to maintain a healthy process. The depuration and biomass production process can be operated in batch or continuous mode, however continuous operation is desired because the light availability into the culture can be kept in an optimal value according to certain cell concentration that is fixed as well. This chemical and biological stability is desirable for long term biotransformation schemes due to the low accumulation of inhibitory compounds and there is not standby times between batches.

\section{CONCLUSION}

Development and implementation of a biorefinery scheme implies not only a list of different value bioproducts obtained through a biological system but also has to include several parts of a process chain. In this study we assessed the feasibility of producing microalgal biomass using brewery low-value sub products as an integrative approach. Although brewing produces a wide variety of wastes, there are only few options useful for algal based bioprocess due to technical and economic reasons. Weak wort fits most of the crucial characteristics such as optical properties, availability and chemical composition but few adjustments are needed before its use a nutrient source for microalgae. For the transformation of high organic load substrates as the one chosen for this work, a microalgae/bacteria consortium is the most convenient biocatalyst because the complementarity between both metabolisms, however, a carefully selection of operation conditions is needed to reach a stable balance between these two organisms. Microbial biomass has a number of different uses like biofuels, fertilizers, biomaterials and nutraceuticals; however, end products in each case strictly depend on the biomass quality and biochemical composition. In this work, we obtained carbohydrate and protein rich biomass from weak wort in a continuous operated photobioreactor, achieving high nutrient removal values and biomass productivity. This biomass can be further analyzed in terms of its suitability to be used as raw material for feed, fertilizers and biopolymers even designed to be applied in the same brewery process.

Funding: This research was funded by the Departamento Administrativo de Ciencia, Tecnología e Innovación Colciencias, Cervecería Union, Fondo de Internacionalización of Universidad de Antioquia and ERANet-LAC1st Joint Call [Grant Number:ELAC2014/BEE-0357].

Conflicts of Interest: The authors declare no conflict of interest. The funders had no role in the design of the study; in the collection, analyses, or interpretation of data; in the writing of the manuscript, or in the decision to publish the results.

\section{REFERENCES}

1 Prochile. Estudio de mercado cerveza en Colombia. 2011: 1-15.

2 Bavaria. Cervecería Union Colombia. 2018.https://www.bavaria.co/acerca-de-nosotros/cerveceria-union-bavaria (accessed 3 Jun2019).

3 Ferreira A, Ribeiro B, Marques PASS, Ferreira AF, Dias AP, Pinheiro HM et al. Scenedesmus obliquus mediated brewery wastewater remediation and CO2 biofixation for green energy purposes. J Clean Prod 2017;165:1316-27. 
4 Giraldo-Calderón ND, Romo-Buchelly RJ, Arbeláez-Pérez AA, Echeverri-Hincapié D, Atehortúa-Garcés L, Atehortúa-Garcés L. Microalgae biorefineries: applications and emerging technologies. DYNA 2018;85:219-33.

5 Salati S, D'Imporzano G, Menin B, Veronesi D, Scaglia B, Abbruscato P et al. Mixotrophic cultivation of Chlorella for local protein production using agro-food by-products. Bioresour Technol 2017;230:82-9.

6 Mata TM, Mendes AM, Caetano NS, Martins AA. Sustainability and economic evaluation of microalgae grown in brewery wastewater. Bioresour Technol 2014;168:151-8.

7 Zheng H, Liu M, Lu Q, Wu X, Ma Y, Cheng Y et al. Balancing carbon/nitrogen ratio to improve nutrients removal and algal biomass production in piggery and brewery wastewaters. Bioresour Technol 2018;249:479-86.

8 Chang Z, Duan P, Xu Y. Catalytic hydropyrolysis of microalgae: Influence of operating variables on the formation and composition of bio-oil. Bioresour Technol 2015;184:349-54.

9 Lima SAC, Raposo MFJ, Castro PML, Morais RM. Biodegradation of $\mathrm{p}$-chlorophenol by a microalgae consortium. Water Res 2004;38:97-102.

10 Zhang J, Hu B, Yiannikouris A, André G, Poughon L, François $\mathrm{J}$ et al. Microalgae in human and animal nutrition. Bioresour Technol 2012;101:1-7.

11 Xia A, Cheng J, Ding L, Lin R, Song W, Zhou J et al. Enhancement of energy production efficiency from mixed biomass of Chlorella pyrenoidosa and cassava starch through combined hydrogen fermentation and methanogenesis. Appl Energy 2014;120:23-30.

12 Strickland JDH, Parsons TR. A practical handbook of seawater analysis. Fisheries Research Board of Canada: Otawa, Ontario, Canadá, 1968.

13 Mukherjee C, Chowdhury R, Sutradhar T, Begam M, Ghosh SM, Basak SK et al. Parboiled rice effluent: A wastewater niche for microalgae and cyanobacteria with growth coupled to comprehensive remediation and phosphorus biofertilization. Algal Res 2016;19:225-36.

14 Cataldo. Determination of nitrate by spectrophotometer. Soil Sci 1975; 6.

15 Dubois M, Gilles K a., Hamilton JK, Rebers P a., Smith F. Colorimetric Method for Determination of Sugars and Related Substances. Anal Chem 1956;28:350-6.

16 Myklestad S, Haug A. Production of carbohydrates by the marine diatom Chaetoceros affinis var. willei (Gran) Hustedt. I. Effect of the concentration of nutrients in the culture medium. BiolEcol 1972;9:125-36.

17 Bligh E, Dyer W. A rapid method of total lipid extraction and purification. Can J Biochem Physiol 1959; 37: 911-917.

18 Lowry O, Rosebrough N, Lewis Farr A, Randall R. Protein measurement with the folin phenol reagent. Readings 1951;193 265-75.

19 Qin C, Liu H, Liu L, Smith S, Sedlak DL, Gu AZ. Bioavailability and characterization of dissolved organic nitrogen and dissolved organic phosphorus in wastewater effluents. Sci Total Environ 2015;511:47-53.

20 Zhang J, Su M, Xi B, Qian G, Liu J, Hua F et al. Algal uptake of dissolved organic nitrogen in wastewater treatment plants. J Environ Sci 2016;50:56-64.

21 Van Wagenen J, De Francisci D, Angelidaki I. Comparison of mixotrophic to cyclic autotrophic/heterotrophic growth strategies to optimize productivity of Chlorella sorokiniana. J Appl Phycol 2015. doi:10.1007/s10811-014-0485-1.

22 Xiong W, Gao C, Yan D, Wu C, Wu Q. Double CO2fixation in photosynthesis-fermentation model enhances algal lipid synthesis for biodiesel production. Bioresour Technol 2010. doi:10.1016/j.biortech.2009.11.041.

23 Wan M, Liu P, Xia J, Rosenberg JN, Oyler GA, Betenbaugh MJ et al. The effect of mixotrophy on microalgal growth, lipid content, and expression levels of three pathway genes in Chlorella sorokiniana. Appl Microbiol Biotechnol 2011. doi:10.1007/s00253-011-3399-8.

24 Wang J, Yang H, Wang F. Mixotrophic cultivation of microalgae for biodiesel production: Status and prospects. Appl. Biochem. Biotechnol. 2014;172:3307-29.

25 Cheirsilp B, Torpee S. Enhanced growth and lipid production of microalgae under mixotrophic culture condition: Effect of light intensity, glucose concentration and fed-batch cultivation. Bioresour Technol 2012;110:510-6.

26 Ren H, Liu B, Kong F, Zhao L, Xie G, Ren N. Bioresource Technology Energy conversion analysis of microalgal lipid production under different culture modes. Bioresour Technol 2014;166: 625-9.

27 Hernández D, Riaño B, Coca M, García-González MC. Treatment of agro-industrial wastewater using microalgaebacteria consortium combined with anaerobic digestion of the produced biomass. Bioresour Technol 2013. doi:10.1016/j.biortech.2012.09.029.

28 Ryu B-G, Kim J, Han J-I, Yang J-W. Feasibility of using a microalgal-bacterial consortium for treatment of toxic coke wastewater with concomitant production of microbial lipids. Bioresour Technol 2017;225:58-66.

29 Cabanelas ITD, Kleinegris DMM, Wijfels RH, Barbosa MJ. Repeated nitrogen starvation doesn't affect lipid productivity of Chlorococcum littorale. Bioresour Technol 2016;219:576-82.

$30 \mathrm{Ho} \mathrm{S}-\mathrm{H}$, Chen C-Y, Chang J-S. Effect of light intensity and nitrogen starvation on CO2 fixation and lipid/carbohydrate production of an indigenous microalga Scenedesmus obliquus CNW-N. Bioresour Technol 2012;113:244-52.

31 Valledor L, Furuhashi T, Recuenco-Muñoz L, Wienkoop S, Weckwerth W. System-level network analysis of nitrogen starvation and recovery in Chlamydomonas reinhardtii reveals potential new targets for increased lipid accumulation. Biotechnol Biofuels 2014;7:171.

32 Rhee G-Y. Effects of N:P atomic ratios and nitrate limitation on algal growth, cell composition, and nitrate uptake 1. Limnol Oceanogr 1978;23:10-25.

33 Wang H, Butt L, Rooks P, Khan F, Allen MJ, Ali ST. Characterisation of algicidal bacterial exometabolites against the lipid-accumulating diatom Skeletonema sp. ALGAL 2016;13:1-6. 
34 Yang C, Hua Q, Shimizu K. Energetics and carbon metabolism during growth of microalgal cells under photoautotrophic, mixotrophic and cyclic light-autotrophic / dark-heterotrophic conditions. Biochem Eng J 2000; 6: 87-102.

35 Andruleviciute V, Makareviciene V, Skorupskaite V, Gumbyte M. Biomass and oil content of Chlorella sp ., Haematococcus sp ., Nannochloris sp . and Scenedesmus sp . under mixotrophic growth conditions in the presence of technical glycerol. J Appl Phycol 2014; 26: 83-90.

(C) 2020 by the authors. Submitted for possible open access publication under the terms and conditions of the Creative Commons Attribution (CC BY NC) license BY NC (https://creativecommons.org/licenses/by-nc/4.0/). 